\title{
Effect of Ethanol on Activity of the Plasma-membrane ATPase in, and Accumulation of Glycine by, Saccharomyces cerevisiae
}

\author{
By CHARLES P. CARTWRIGHT, FELICITY J. VEAZEY \\ AND ANTHONY H. ROSE* \\ Zymology Laboratory, School of Biological Sciences, University of Bath, Bath, \\ Avon BA2 7AY, UK
}

(Received 20 August 1986; revised 29 October 1986)

\begin{abstract}
The $\mathrm{pH}$ optimum of the ATPase activity in plasma membranes from Saccharomyces cerevisiae NCYC 431 from $8 \mathrm{~h}$ cultures was around 6.5 and that in membranes from organisms from $16 \mathrm{~h}$ cultures near 6.0 . The $K_{\mathrm{m}}$ [ATP] of the enzyme was virtually unaffected by the age of the culture from which organisms were harvested, although the $V_{\max }$ of the enzyme in membranes from organisms from $8 \mathrm{~h}$ cultures was higher than that for organisms from $16 \mathrm{~h}$ cultures. Ethanol noncompetitively inhibited ATPase activity in membranes, although the inhibition constant for the enzyme from organisms from $8 \mathrm{~h}$ cultures was lower than that from organisms from $16 \mathrm{~h}$ cultures. Glycine accumulation by the general amino acid permease was non-competitively inhibited by ethanol. Inhibition constants were virtually the same for glycine uptake by deenergized organisms from $8 \mathrm{~h}$ and $16 \mathrm{~h}$ cultures, but under energized conditions the value was greater for organisms from $16 \mathrm{~h}$ rather than $8 \mathrm{~h}$ cultures. The data indicate that inhibition of plasma-membrane ATPase activity by ethanol could account, at least in part, for inhibition of glycine accumulation by ethanol.
\end{abstract}

\section{INTRODUCTION}

Three distinct ATPase enzymes are synthesized by Saccharomyces cerevisiae. In addition to the plasma-membrane enzyme, both mitochondrial (Schatz et al., 1967) and vacuolar membranes (van der Wilden \& Matile, 1978) possess ATPase activity. The properties of the plasma-membrane ATPase of $S$. cerevisiae have been well documented (Goffeau \& Slayman, 1981). The enzyme has a relatively low pH optimum of 5.5-6.5 (Willsky, 1979; Borst-Pauwels \& Peters, 1981), an absolute requirement for $\mathrm{Mg}^{2+}$ (Ahlers et al., 1978; Willsky, 1979) and a high substrate specificity (Serrano, 1978; Peters \& Borst-Pauwels, 1979). In addition, it shows differential sensitivity to a number of inhibitors. Oligomycin, an inhibitor of the mitochondrial ATPase (Serrano, 1978), has little effect on the plasma-membrane ATPase, whereas orthovanadate (Willsky, 1979) and diethylstilboestrol (Serrano, 1980), which do not inhibit the mitochondrial ATPase, are potent inhibitors of the plasma-membrane enzyme. DCCD inhibits all three ATPases in $S$. cerevisiae, although the mitochondrial and vacuolar enzymes are approximately ten times more sensitive to this inhibitor than the plasma-membrane ATPase (Serrano, 1978; Okorokov et al., 1982). The plasma-membrane ATPase in S. cerevisiae functions as an electrogenic proton pump (Malpartida \& Serrano, 1981; Dufour et al., 1982) coupling ATP hydrolysis to translocation of protons across the membrane, resulting in the establishment of a transmembrane proton electrochemical gradient $(\Delta p)$.

The $\Delta p$ has been shown to energize active transport of solutes by $S$. cerevisiae (Borst-Pauwels, 1981 ; Eddy, 1982). When grown in the presence of ammonium ions this yeast synthesizes at least

\footnotetext{
Abbreviations: DCCD, $N, N^{\prime}$-dicyclohexylcarbodiimide; GAP, general amino acid permease; $\Delta p$, protonmotive force.
} 
10 amino acid transport systems, each of which is specific for one or a small number of L-amino acids (Eddy, 1982). Very little has been reported on transport of glycine by a specific system, and it is generally assumed that transport of this amino acid is effected mainly by the general amino acid permease (GAP), a high-velocity broad-specificity system capable of transporting L- and Damino acids (Rytka, 1975) and subject to nitrogen catabolite repression (Grenson et al., 1970). Two kinetically distinct systems for glycine accumulation by $S$. cerevisiae, a high-affinity system which was assumed to be the GAP and a low-affinity system, have been described (Eddy et al., 1970; Ballarin-Denti et al., 1984). Accumulation of glycine by the GAP has been extensively studied. This amino acid can accumulate in $S$. cerevisiae to a concentration as high as 1400 times that outside the organism (Eddy et al., 1970), a proportion of this being accumulated in the vacuole (Indge et al., 1977). Two or more protons are transported intracellularly with each glycine molecule (Seaston et al., 1973), although under some conditions only one extracellular proton-binding site dissociates (Ballarin-Denti et al., 1984).

Inhibition of growth of $S$. cerevisiae by ethanol is thought to be caused, at least in part, by interaction of ethanol with the plasma membrane (Ingram \& Buttke, 1984). This interaction probably accounts for the non-competitive inhibition, by ethanol, of solute accumulation by this organism (Thomas \& Rose, 1979; Leão \& van Uden, 1982, 1983, 1984; Loureiro-Dias \& Peinado, 1982). Since most transport processes are active and require a $\Delta p$ (Borst-Pauwels, 1981 ; Serrano, 1977), the effect of ethanol on the ability of $S$. cerevisiae to maintain a $\Delta p$ across the plasma-membrane was examined. Cartwright et al. (1986) have shown that ethanol, up to a concentration of $2.0 \mathrm{M}$, partially dissipates the $\Delta p$ across the plasma membrane of $S$. cerevisiae NCYC 431 and, under conditions where the plasma-membrane ATPase is active, this dissipation is more pronounced in organisms from mid-exponential phase $(8 \mathrm{~h})$ compared with early stationary phase $(16 \mathrm{~h})$ cultures.

The present paper reports on the effect of ethanol on the activity of the plasma-membrane ATPase in S. cerevisiae NCYC 431, and on the possible relationship between ethanol-induced inhibition of this enzyme and retardation of glycine accumulation caused by ethanol.

\section{METHODS}

Organism. The strain of $S$. cerevisiae used in this study, NCYC 431 (Beavan et al., 1982), was maintained on slopes of malt extract/yeast extract/glucose/mycological peptone (MYGP) medium (Wickerham, 1951) solidified with $2 \%(\mathrm{w} / \mathrm{v})$ agar. A mutant $(\mathrm{CCl})$ lacking GAP activity was isolated by a modification of the method of Rytka (1975) as described by Gregory et al. (1982). It was maintained on slopes of defined medium (Gregory et al. 1982) supplemented with D-methionine $\left(20 \mathrm{mg} \mathrm{l}^{-1}\right)$.

Experimental cultures. All experiments were done with organisms from self-induced anaerobic cultures grown as described by Beavan et al. (1982). Organisms were harvested as described by Cartwright et al. (1986) after approximately $8 \mathrm{~h}\left(0.28 \mathrm{mg}\right.$ dry $\left.\mathrm{wt} \mathrm{ml}^{-1}\right)$ or $16 \mathrm{~h}\left(2.4 \mathrm{mg}\right.$ dry $\left.\mathrm{wt} \mathrm{ml}^{-1}\right)$ incubation.

Isolation of plasma membranes. Plasma membranes were isolated from spheroplasts that had been surfacelabelled with cationic silica microbeads (Schmidt et al., 1983). To prepare spheroplasts, organisms were washed once in water, then in buffered sorbitol $\left(20 \mathrm{~mm}\right.$-Tris containing $10 \mathrm{mM}-\mathrm{MgCl}_{2}, 1 \cdot 2 \mathrm{M}$-sorbitol and $0 \cdot 1 \mathrm{mM}$-sodium metabisulphite; $\mathrm{pH} \mathrm{7.2)} \mathrm{and} \mathrm{suspended} \mathrm{in} \mathrm{the} \mathrm{same} \mathrm{buffer} \mathrm{to} 10 \mathrm{mg}$ dry wt $\mathrm{ml}^{-1}$. Zymolyase 100000 was then added $\left[0.1 \mathrm{mg}(10 \mathrm{mg} \text { dry } w \mathrm{t} \text { organism })^{-1}\right]$ and the suspension incubated at $30^{\circ} \mathrm{C}$ with reciprocal shaking (120 r.p.m.). After incubation for $1 \mathrm{~h}$, a check that formation of spheroplasts was complete was made by diluting $0.1 \mathrm{ml}$ portions of the suspension into $2.9 \mathrm{ml}$ of either $1.2 \mathrm{M}$-sorbitol or water and measuring the optical density at $600 \mathrm{~nm}$. Spheroplasts were washed three times in coating buffer ( $1.2 \mathrm{M}$-sorbitol containing $25 \mathrm{~mm}$-sodium acetate and $0.1 \mathrm{M}-\mathrm{KCl} ; \mathrm{pH} 6.0$ ), the population counted and then suspended in coating buffer to $1.5 \times 10^{8}$ spheroplasts $\mathrm{ml}^{-1}$. Suspensions of spheroplasts and microbeads $(3 \%, \mathrm{w} / \mathrm{v}$, in coating buffer) were mixed in the ratio $2: 1$. After incubation for $3 \mathrm{~min}$ at $4^{\circ} \mathrm{C}$ the suspension of coated spheroplasts was centrifuged $(500 \mathrm{~g} ; 4 \mathrm{~min})$, the spheroplasts washed once in coating buffer and then suspended in the same buffer to a concentration of $10^{8}$ spheroplasts $\mathrm{ml}^{-1}$. This suspension was diluted with an equal volume of coating buffer containing $2 \mathrm{mg}$ polyacrylic acid $\left(M_{\mathrm{r}} 90000\right)$ $\mathrm{ml}^{-1}$, and spheroplasts were washed once with coating buffer. The spheroplasts were then resuspended in lysis buffer (5 mM-Tris/HCl containing $1 \mathrm{mM}$-EGTA; $\mathrm{pH} \mathrm{8.0)}$ to $10^{8}$ spheroplasts $\mathrm{ml}^{-1}$ and the suspension vortexed for 5 min causing at least $95 \%$ lysis of spheroplasts. The lysate was centrifuged $(1000 \mathrm{~g} ; 5 \mathrm{~min})$, the pellet of plasma membrane washed three times in lysis buffer and then suspended in assay buffer ( $100 \mathrm{mM}-\mathrm{MES} /$ Tris containing 80 $\mathrm{mM}-\mathrm{KCl} ; \mathrm{pH} 6.5)$. The protein content of the plasma-membrane preparation was assayed using the Bio- $\mathrm{Rad}$ protein assay, based on the dye-binding technique of Bradford (1976). Portions (0.1 ml) of plasma-membrane 
preparation were solubilized by boiling for $5 \mathrm{~min}$ after addition of an equal volume of $0 \cdot 1 \mathrm{M}-\mathrm{NaOH}$. The solution was then neutralized by addition of $0.1 \mathrm{M}-\mathrm{HCl}(0.1 \mathrm{ml})$ and $0.2 \mathrm{ml}$ acetic acid/sodium acetate buffer $(0.2 \mathrm{M}$; $\mathrm{pH} 5 \cdot 0$ ). The amount of protein in samples was calculated using bovine serum albumin as a standard

Assay of ATPase activity. Plasma-membrane ATPase activity was assayed by following release of $P_{i}$ from ATP. The reaction mixture consisted of $1 \mathrm{ml} 100 \mathrm{mM}-\mathrm{MES} / \mathrm{Tris}$ buffer containing $80 \mathrm{mM}-\mathrm{KCl}, 0.25-6.0 \mathrm{mM}-\mathrm{MgCl}_{2}$ and plasma-membrane preparation containing 25-50 $\mathrm{g}$ protein. Except when otherwise indicated, the $\mathrm{pH}$ of the buffer was 6.0 for membrane preparations from $16 \mathrm{~h}$ cultures and 6.5 for preparations from $8 \mathrm{~h}$ cultures. ATP concentrations were varied over the range $0 \cdot 25-6.0 \mathrm{mM}$ and, in all reaction mixtures, the ATP: $\mathrm{Mg}^{2+}$ ratio was maintained at unity. The reaction was started by adding ATP (sodium salt) and the mixture incubated for 10-40 min at $30{ }^{\circ} \mathrm{C}$. The amount of $P_{i}$ liberated was determined as described by Serrano (1978). The reaction was stopped by adding $2 \mathrm{ml}$ of $2.0 \%(\mathrm{v} / \mathrm{v})$ conc. $\mathrm{H}_{2} \mathrm{SO}_{4}$ containing $0.5 \%(\mathrm{w} / \mathrm{v})$ ammonium molybdate and $0.5 \%$ (w/v) SDS. Ascorbic acid $(0.02 \mathrm{ml} ; 10 \%, \mathrm{w} / \mathrm{v})$ was then added and the colour allowed to develop over $5 \mathrm{~min}$ at $30{ }^{\circ} \mathrm{C}$. The absorbance of the solution was measured at $750 \mathrm{~nm}$ and the value related to $P_{i}$ concentration by a standard curve. ATPase activity is quoted as $\mu \mathrm{mol} P_{i}$ released (mg protein $)^{-1} \mathrm{~min}^{-1}$. To examine the effect of ethanol on ATPase activity, the alkanol $(95 \%, \mathrm{v} / \mathrm{v})$ was included in suspensions of plasma membrane in assay buffer to give final concentrations of $0.5,1.0,1.5$ and $2.0 \mathrm{M}$. After $5 \mathrm{~min}$ incubation at $30^{\circ} \mathrm{C}$, the reaction was started by addition of ATP. ATPase inhibitors were similarly included in the membrane suspensions over a suitable range of concentrations and incubated for $10 \mathrm{~min}$ before starting the reaction.

Measurement of velocity of glycine accumulation. Organisms from $8 \mathrm{~h}$ or $16 \mathrm{~h}$ cultures were washed twice with citric acid/trisodium citrate buffer ( $20 \mathrm{mM} ; \mathrm{pH} \mathrm{4.0)}$ suspended at $5 \mathrm{mg} \mathrm{dry} \mathrm{wt} \mathrm{ml}^{-1}$ in the same buffer and stored in an ice-water mixture. The suspension $(5 \mathrm{ml})$ used to measure the velocity of glycine accumulation consisted of citrate buffer ( $20 \mathrm{~mm} ; \mathrm{pH} 4.0)$ containing $2.5 \mathrm{mg}$ dry wt organisms $\mathrm{ml}^{-1}$ and was maintained at $30^{\circ} \mathrm{C}$ in a waterbath and stirred continuously. Glucose $(100 \mathrm{~mm})$ or 2-deoxy-D-glucose (20 mM) was included in the suspension as indicated, as was ethanol to a final concentration of $0.5,1.0,1.5$ or $2.0 \mathrm{M}$. After 5 min incubation, the experiment was started by addition of $\left[\mathrm{U}^{-14} \mathrm{C}\right] \mathrm{glycine}\left[10^{-3}-10^{-6} \mathrm{M} ; 0 \cdot 1-1 \cdot 0 \mu \mathrm{Ci} \mu \mathrm{mol}^{-1}\left(3 \cdot 7-37 \mathrm{kBq}^{-1} \mathrm{~mol}^{-1}\right)\right]$ after which portions $(0.75 \mathrm{ml})$ were removed at predetermined times, rapidly filtered through membrane filters $(0.45 \mu \mathrm{m}$ pore size; $25 \mathrm{~mm}$ diameter; Millipore) and the filter and cells immediately washed with ice-cold citrate buffer ( $5 \mathrm{ml} ; \mathrm{pH}$ 4.0) containing glycine at the concentration included in the suspension. Filters were then transferred to scintillation vials containing $7.5 \mathrm{ml}$ Optiphase Safe (Fisons) and radioactivity measured in a liquid scintillation spectrometer (LKB Rackbeta, model 1217). Velocities of accumulation were determined from the linear segments of plots of the time-course of accumulation for up to $60 \mathrm{~s}$.

Determination of the phospholipid composition of plasma membranes and of the fatty-acyl composition of phospholipids. A plasma membrane-cationic microbead preparation from $500 \mathrm{mg}$ dry wt organisms was taken up in 15-20 ml methanol, to which chloroform was added to give a chloroform/methanol ratio of $2: 1(\mathrm{v} / \mathrm{v})$. Nonspecific lipase activity was inhibited by inclusion of $1 \mathrm{~mm}$-p-chloromercuribenzoate, and the suspension was stirred for $2 \mathrm{~h}$ at room temperature. Extracts were washed with $0.25 \mathrm{vol} .0 .88 \%(\mathrm{w} / \mathrm{v}) \mathrm{KCl}$ and allowed to separate overnight at $-20^{\circ} \mathrm{C}$. The lower phase was removed, dried on a rotary evaporator and the residue immediately dissolved in a minimum of chloroform. Phospholipids were separated from other lipid classes by TLC on plates of silica gel $\mathrm{G}$ (Whatman; $0 \cdot 25 \mathrm{~mm}$ thick), using a solvent system of light petroleum (b.p. $60-80^{\circ} \mathrm{C}$ ) $/$ diethyl ether/acetic acid $\left(70: 30: 1\right.$, by vol.). Bands of lipid classes were visualized by spraying with $0 \cdot 2^{\circ} \%(w / v) 2^{\prime}, 7^{\prime}-$ dichlorofluorescein in ethanol, and then viewing plates under UV light $(254 \mathrm{~nm})$. Individual lipid classes were identified by reference to simultaneously run standards. Bands containing phospholipid classes were scraped off and suspended in $10 \mathrm{ml}$ light petroleum/methanol $(1: 1, \mathrm{v} / \mathrm{v})$. The suspension was vigorously shaken, $5 \mathrm{ml} 30 \%$ $(w / v) ~ N a C l$ added, the suspension allowed to separate at room temperature, and the upper layer removed and retained. A further $5 \mathrm{ml}$ light petroleum was added, and the extraction procedure repeated. The combined extracts were dried under nitrogen, the residue taken up in $0.3 \mathrm{ml}$ chloroform, and individual phospholipid classes separated by TLC using a solvent system of chloroform/methanol/acetic acid (65:25:8, by vol.; Kramer $e$ t al., 1978). Individual phospholipid classes were visualized by spraying plates with $4 \cdot 2 \mathrm{M}-\mathrm{H}_{2} \mathrm{SO}_{4}$ containing $0.65 \%$ (w/v) molybdenum oxide (Dittmer \& Lester, 1964) and identified by reference to standards. The relative proportions of the major phospholipid classes were determined using a scanning densitometer (Joyce Loebl Chromoscan 3; wavelength $626 \mathrm{~nm}$; aperture width $0 \cdot 1-0.3 \mathrm{~mm}$ ). To determine the fatty-acyl composition of phospholipid classes, bands were visualized and identified as described above, and scraped off. Fatty-acyl methyl esters were prepared by heating $\left(80^{\circ} \mathrm{C}, 60 \mathrm{~min}\right)$ the silica gel with $5 \mathrm{ml}$ methanol containing $14 \%(\mathrm{w} / \mathrm{v}) \mathrm{BF}_{3}$ in a Reactivial (Pierce). After cooling, the solution was extracted twice with light petroleum $/ \mathrm{methanol} / 30 \%(\mathrm{w} / \mathrm{v})$ $\mathrm{NaCl}(1: 1: 1$, by vol.). Fatty acid methyl esters were analysed by GLC on a column $(1.5 \mathrm{~m})$ containing $10 \% \mathrm{~S} 2330$ supported on 100-200 mesh Chromosorb W-AW at $165^{\circ} \mathrm{C}$. The injection port was at $210^{\circ} \mathrm{C}$, the detector temperature was $190^{\circ} \mathrm{C}$ and the carrier gas $\left(\mathrm{N}_{2}\right)$ flow rate was $60 \mathrm{ml} \mathrm{min}{ }^{-1}$. Percentage fatty acid compositions were calculated using a Pye Unicam CDPl integrator.

Electron microscopy. The purity of plasma-membrane preparations was examined by transmission electron microscopy using a modification of the method of Henschke et al. (1983). 


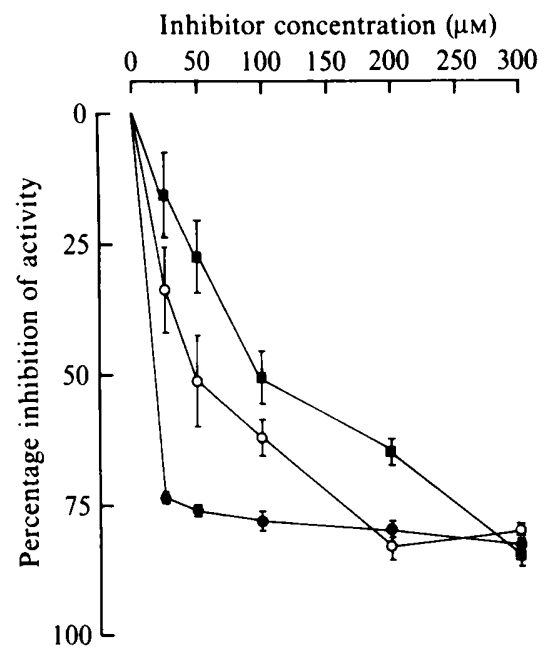

Fig. 1

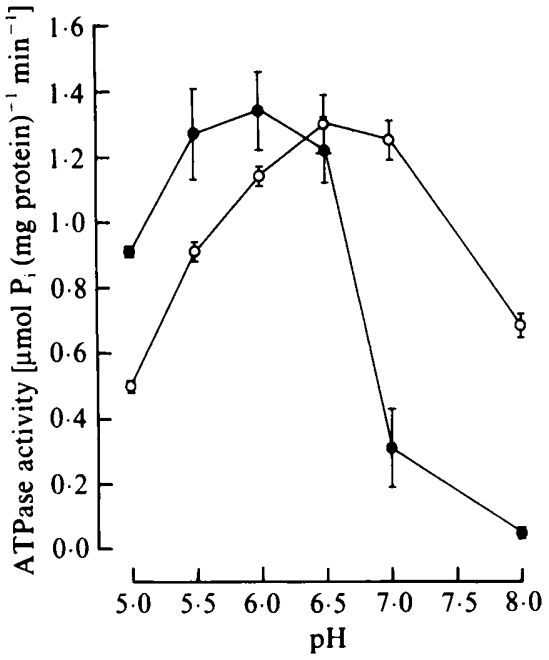

Fig. 2

Fig. 1. Effect of inhibitors ( $O$, sodium orthovanadate; $O$, diethylstilboestrol; $\square, D C C D)$ on the ATPase activity of plasma membranes from 8 h cultures of $S$. cerevisiae NCYC 431.

Fig. 2. Effect of pH on the ATPase activity of plasma membranes from $8 \mathrm{~h}(\mathrm{O})$ and $16 \mathrm{~h}(\mathrm{O})$ cultures of $S$. cerevisiae NCYC 431 .

Chemicals. All chemicals used were Analar or of the highest purity available commercially. Cationic silica microbeads were supplied by B. Jacobson, Department of Biochemistry, University of Massachusetts, Amherst, MA 01003, USA.

\section{RESULTS}

\section{Properties of the plasma-membrane ATPase}

Plasma-membrane preparations appeared essentially free from contamination with nonmembraneous and mitochondrial material when examined in the electron microscope. ATPase activity of membranes was inhibited by sodium orthovanadate, diethylstilboestrol and DCCD to an extent virtually identical with membranes from organisms from $8 \mathrm{~h}$ (Fig. 1) and $16 \mathrm{~h}$ cultures (data not shown). Oligomycin, at concentrations up to $300 \mu \mathrm{g} \mathrm{ml}^{-1}$, caused less than $5 \%$ inhibition of ATPase activity in membranes from organisms from $8 \mathrm{~h}$ and $16 \mathrm{~h}$ cultures. The $\mathrm{pH}$ optimum of the ATPase activity in membranes from organisms from $8 \mathrm{~h}$ cultures was around 6.5 , while the optimum for the activity in membranes from organisms from $16 \mathrm{~h}$ cultures was near 6.0 (Fig. 2). Values for $K_{\mathrm{m}}$, derived from Hanes (1932) plots, for ATPase activity of membranes from $8 \mathrm{~h}$ and $16 \mathrm{~h}$ cultures were virtually identical, whereas $V_{\max }$ values differed (Table 1). Ethanol, at concentrations up to $2.0 \mathrm{M}$, inhibited ATPase activity in membranes from organisms from both $8 \mathrm{~h}$ and $16 \mathrm{~h}$ cultures, although the inhibition constant $K_{\mathrm{i}}$ derived from Dixon (1953) plots was different for the two preparations (Table 1).

\section{Phospholipid and fatty-acyl compositions of plasma-membranes}

Phosphatidylethanolamine and phosphatidylcholine were the principal phospholipids in plasmamembranes, the former being present in greater proportion in membranes from organisms from $8 \mathrm{~h}$ compared with $16 \mathrm{~h}$ cultures (Table 2). Phosphatidylinositol was present in about the same proportion in membranes from organisms from $8 \mathrm{~h}$ and $16 \mathrm{~h}$ cultures while the proportions of phosphatidylserine differed. The fatty-acyl composition of individual plasmamembrane phospholipids differed in organisms from $8 \mathrm{~h}$ as compared with $16 \mathrm{~h}$ cultures, the proportion of unsaturation decreasing with culture age (Table 3). Of the four major phospholipids detected, phosphatidylinositol showed greatest conservation of fatty-acyl unsaturation with culture age. 
Table 1. Kinetic constants for the plasma-membrane ATPase of S. cerevisiae NCYC 431

$K_{\mathrm{m}}$ and $V_{\max }$ values were derived from Hanes (1932) plots and $K_{\mathrm{i}}$ values from Dixon (1953) plots. Values are means of at least three independent investigations \pm SE.

\section{Constant}

$K_{\mathrm{m}}[\mathrm{ATP}](\mathrm{mM})$

$V_{\max }\left[\mu \mathrm{mol}(\mathrm{mg} \text { protein })^{-1} \mathrm{~min}^{-1}\right]$

$K_{\mathrm{i}}[\mathrm{EtOH}](\mathrm{M})$
Value for enzyme from organisms grown for:

$\begin{array}{cc}\overbrace{8 \mathrm{~h}} & 16 \mathrm{~h} \\ 2.47 \pm 0.08 & 2.62 \pm 0.32 \\ 1.97 \pm 0.09 & 1.33 \pm 0.02 \\ 1.87 \pm 0.12 & 2.19 \pm 0.08\end{array}$

Table 2. Phospholipid composition of plasma membranes from $S$. cerevisiae grown for $8 \mathrm{~h}$ or $16 \mathrm{~h}$

Phospholipid

Phosphatidylethanolamine

Phosphatidylcholine

Phosphatidylinositol

Phosphatidylserine

Percentage of total phospholipid*

Organisms grown for:

$8 \mathrm{~h}$

\begin{tabular}{|c|c|}
\hline $46 \cdot 32 \pm 5 \cdot 44$ & $31 \cdot 14 \pm 2 \cdot 24$ \\
\hline $32.01 \pm 3.60$ & $35.28 \pm 4.23$ \\
\hline $18 \cdot 49 \pm 3 \cdot 11$ & $20 \cdot 37 \pm 5 \cdot 13$ \\
\hline $3.06 \pm 0.33$ & 12.94 \\
\hline
\end{tabular}

* Values quoted are $\pm \mathrm{SE}$.

Table 3. Fatty-acyl composition of phospholipids in plasma membranes of S. cerevisiae NCYC 431 harvested after $8 \mathrm{~h}$ or $16 \mathrm{~h}$ incubation

Abbreviations: PC, phosphatidylcholine; PE, phosphatidylethanolamine; PI, phosphatidylinositol; PS, phosphatidylserine.

Percentage of the total phospholipid class in organisms from cultures grown for*:

\begin{tabular}{|c|c|c|c|c|c|c|c|c|}
\hline \multirow{2}{*}{$\begin{array}{l}\text { Fatty- } \\
\text { acyl } \\
\text { residue }\end{array}$} & \multicolumn{4}{|c|}{$8 \mathrm{~h}$} & \multicolumn{4}{|c|}{$\overbrace{}^{16 \mathrm{~h}}$} \\
\hline & PC & PE & PI & PS & PC & PE & PI & PS \\
\hline $12: 0$ & $1.98 \pm 0.46$ & $0.23 \pm 0.08$ & $0.41 \pm 0.29$ & $1.83 \pm 0.16$ & $1.34 \pm 0.61$ & $0.82 \pm 0.18$ & $1.71 \pm 0.42$ & $3.83 \pm 0.67$ \\
\hline $14: 0$ & $2.14 \pm 0.14$ & $1.92 \pm 0.33$ & $1.10 \pm 0.11$ & $1.73 \pm 0.21$ & $2.79 \pm 0.27$ & $1.85 \pm 0.21$ & $2.48 \pm 0.53$ & $3.26 \pm 0.43$ \\
\hline $14: 1$ & $0.71 \pm 0.15$ & $0.22 \pm 0.05$ & $0.81 \pm 0.09$ & $1.37 \pm 0.22$ & $1.38 \pm 0.15$ & $0.68 \pm 0.10$ & $1.69 \pm 0.37$ & $1 \cdot 00 \pm 0.36$ \\
\hline $16: 0$ & $22.70 \pm 2.27$ & $28.98 \pm 1.21$ & $32.49 \pm 1.63$ & $38.82 \pm 1.75$ & $33.55 \pm 1.44$ & $26.92 \pm 2.64$ & $27.40 \pm 3.14$ & $40.67 \pm 5.04$ \\
\hline $16: 1$ & $46.22 \pm 2.17$ & $42.06 \pm 1.78$ & $28.67 \pm 0.87$ & $20.32 \pm 3.80$ & $34.25 \pm 0.93$ & $42.19 \pm 4.47$ & $31.19 \pm 1.34$ & $15.23 \pm 3.25$ \\
\hline $18: 0$ & $4.41 \pm 0.90$ & $3.92 \pm 0.24$ & $9.30 \pm 1.58$ & $24.37 \pm 2.95$ & $9.73 \pm 1.67$ & $7.67 \pm 0.56$ & $16.91 \pm 0.79$ & $23 \cdot 39 \pm 3 \cdot 10$ \\
\hline $18: 1$ & $21.69 \pm 1.53$ & $30.40 \pm 2.04$ & $26.72 \pm 2.52$ & $11.42 \pm 1.41$ & $16.95 \pm 2.01$ & $20.69 \pm 1.99$ & $18.01 \pm 2.24$ & $11.09 \pm 1.50$ \\
\hline$\Delta \mathrm{mol}^{-1}$ & 0.69 & 0.73 & 0.56 & 0.33 & 0.53 & 0.64 & 0.51 & 0.27 \\
\hline
\end{tabular}

\section{Effect of ethanol on glycine accumulation}

Woolf-Hofstee (Hofstee, 1959) plots showed that organisms possessed two separable glycine accumulation systems, which differ in affinity for glycine and in velocity of solute accumulation (Table 4). The high-affinity system was not detectable in the GAP-less mutant. Ethanol inhibited glycine accumulation by the high-affinity system in energized and de-energized organisms. The inhibitory effect on glycine accumulation closely paralleled the decrease in $\Delta p$ caused by ethanol (Cartwright et al., 1986). This correspondence was observed with organisms from $8 \mathrm{~h}$ (Fig. 3) and $16 \mathrm{~h}$ cultures (data not shown) and in suspensions containing 50-100 $\mathrm{MM}$ glycine. Values for $K_{\mathrm{i}}$ (Dixon, 1953) were virtually the same for de-energized organisms from $8 \mathrm{~h}$ $(0.71 \pm 0.09 \mathrm{M})$ and $16 \mathrm{~h}(0.74 \pm 0.08 \mathrm{M})$ cultures, but with energized organisms the value was greater for organisms from $16 \mathrm{~h}$ cultures $(1.55 \pm 0.11 \mathrm{M})$ compared with $8 \mathrm{~h}$ cultures $(0.97 \pm 0.10 \mathrm{M})$. (Values are means $\pm \mathrm{SE}$.) 


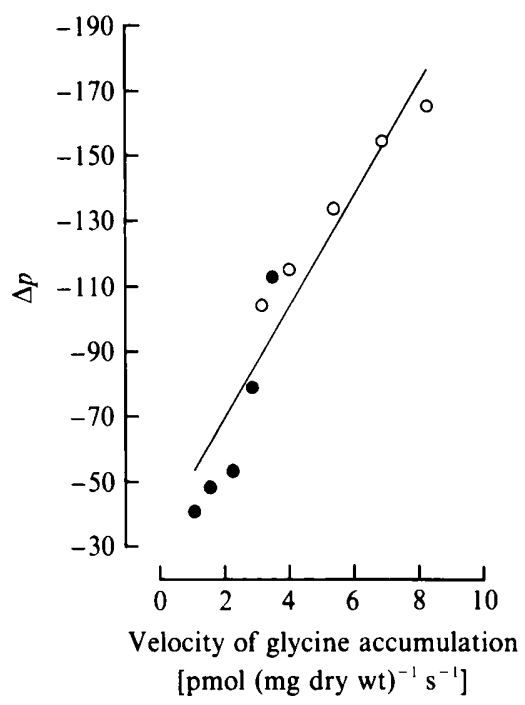

Fig. 3. Relationship between the effect of ethanol on the velocity of glycine accumulation by the GAP and on the $\Delta p$ generated by $S$. cerevisiae NCYC 431 harvested from $8 \mathrm{~h}$ cultures. $O$, Response of deenergized organisms; $O$, response of energized organisms. Data are for glycine accumulation from a suspension containing $100 \mu \mathrm{M}$-glycine. Values for the $\Delta p$ are from Cartwright et al. (1986). The correlation coefficient for the data shown is $\mathbf{0 . 9 5}$, and that for data on organisms from $16 \mathrm{~h}$ cultures (not shown) $0 \cdot 81$.

Table 4. Kinetic constants for accumulation of glycine by S. cerevisiae NCYC 431

\begin{tabular}{|c|c|c|c|}
\hline \multirow[b]{2}{*}{ Value } & \multirow{2}{*}{$\begin{array}{l}\text { Affinity } \\
\text { system }\end{array}$} & \multicolumn{2}{|c|}{$\begin{array}{l}\text { Values for organisms from cultures } \\
\text { grown for*: }\end{array}$} \\
\hline & & $8 \mathrm{~h}$ & $16 \mathrm{~h}$ \\
\hline$K_{\mathrm{T}}(\mathrm{mM})$ & $\begin{array}{l}\text { High } \\
\text { Low }\end{array}$ & $\begin{array}{l}0.06 \pm 0.02 \\
2.25 \pm 0.04\end{array}$ & $\begin{array}{l}0.09 \pm 0.04 \\
2.86 \pm 0.08\end{array}$ \\
\hline$V_{\max }\left[\mathrm{pmol}(\mathrm{mg} \text { dry } \mathrm{wt})^{-1} \mathrm{~s}^{-1}\right]$ & $\begin{array}{l}\text { High } \\
\text { Low }\end{array}$ & $\begin{array}{r}7.80 \pm 0.96 \\
275.9 \pm 18.6\end{array}$ & $\begin{aligned} 8.21 & \pm 1.52 \\
1352.8 & \pm 26.9\end{aligned}$ \\
\hline
\end{tabular}

* Values were corrected as described by Neal (1972), and are quoted \pm SE.

\section{DISCUSSION}

Electron microscopy confirmed that plasma membranes of $S$. cerevisiae, isolated using cationically charged microbeads, were free from contaminating material derived from other yeast organelles. Furthermore, the effects of inhibitors on the activity of the plasma-membrane ATPase, an enzyme often taken as a marker for the yeast plasma membrane, attest the purity of the preparations obtained. One of the main advantages of using microbeads to isolate plasma membranes from eukaryotic micro-organisms is that the time taken to obtain reasonably pure preparations is much shorter than when differential centrifugation and density-gradient methods are employed. Shortening of the preparation time might decrease the extent to which membrane lipids are degraded during isolation. It was therefore of interest to compare the lipid composition of membranes obtained using microbeads with those reported for preparations obtained using alternative techniques. The proportions of phospholipid classes in plasma membranes were very similar to those discovered by Longley et al. (1968), and Suomalainen \& Nurminen (1970). Moreover, the changes that occurred in the overall fatty-acyl composition of plasma-membrane phospholipids as cultures progressed from the exponential to the stationary phase of growth were similar to those reported by Beavan et al. (1982) for whole-cell 
phospholipids, suggesting that culture age has a similar effect on the degree of unsaturation of phospholipids in most types of yeast membrane. Our study also revealed that changes in the relative proportions of phospholipids and in the fatty-acyl composition of individual classes of plasma-membrane phospholipid accompany the transition from the exponential to the stationary phase of growth. The relative proportions of phosphatidylethanolamine and phosphatidylserine, but not of phosphatidylcholine or phosphatidylinositol, in plasma membranes varied with culture age. Interestingly, only phosphatidylinositol retained the same degree of fatty-acyl unsaturation in plasma membranes from organisms from $8 \mathrm{~h}$ and $16 \mathrm{~h}$ cultures. This suggests that this phospholipid supports some plasma-membrane function which, associated with a critical degree of fatty-acyl unsaturation, is of physiological importance to the yeast.

Since ethanol dissipates the $\Delta p$ across the plasma membrane of $S$. cerevisiae NCYC 431 (Cartwright et al.,1986), one objective of the present study was to assess to what extent this dissipation is caused by an inhibitory effect of ethanol on the plasma-membrane ATPase. Our finding that ethanol non-competitively inhibited ATPase activity in the same range of concentrations at which it dissipated the $\Delta p$ suggests that inhibition of this enzyme is a major factor in determining the extent of $\Delta p$ dissipation. That the $V_{\max }$ value for the ATPase in membranes from organisms from $16 \mathrm{~h}$ cultures was lower than the corresponding value for membranes from organisms from $8 \mathrm{~h}$ cultures, while the $K_{\mathrm{m}}$ value remained unchanged, confirms the report by Tuduri et al. (1985) of a decline in the activity of this enzyme during the late exponential phase of growth. This effect, and also the change in the optimum $\mathrm{pH}$ value for the membrane-bound ATPase activity, are conceivably results of alterations that take place in the phospholipid and fatty-acyl compositions of the plasma membrane with culture age. In this context, Stadtlander et al. (1982) showed that changes in phospholipid head-group orientation as well as in fatty-acyl chain length and degree of unsaturation modify kinetic characteristics of the yeast plasma-membrane ATPase.

To determine the extent to which ethanol-induced inhibition of active uptake of solutes might be attributable to the dissipative effect of ethanol on the $\Delta p$, glycine was chosen as the solute to be studied. Ballarin-Denti et al. (1984) reported that glycine accumulation by $S$. cerevisiae had no appreciable effect on intracellular $\mathrm{pH}$ value, even under de-energized conditions. Consequently, uptake of glycine by $S$. cerevisiae NCYC 431 should not alter the values for the $\Delta p$ previously determined for this strain (Cartwright et al., 1986). Our data on glycine accumulation confirm the claims by Eddy et al. (1970) and Ballarin-Denti et al. (1984) that $S$. cerevisiae possesses two distinct uptake systems for this amino acid. However, using the GAP-less mutant, we were able to show conclusively that the high-affinity system, which was examined further in the present study, was the GAP. The nature of the low-affinity glycine-uptake system remains unclear although, given the high $K_{\mathrm{T}}$ and low $V_{\max }$ values for glycine accumulation by this carrier, it probably functions primarily to transport some other amino acid or acids.

Our data on the effect of ethanol on glycine accumulation agree with the report of Leão \& van Uden (1984) that inhibition of GAP activity is non-competitive. Leão \& van Uden (1984) suggested that ethanol inhibits glycine transport by altering the conformation of the transport protein(s). An alternative explanation is that ethanol inhibits glycine accumulation as a result of its dissipative effect on the $\Delta p$. Our belief is that this effect at least partly accounts for ethanolinduced inhibition of glycine accumulation by $S$. cerevisiae. The finding that ethanol has a greater inhibitory effect on glycine accumulation by organisms from $8 \mathrm{~h}$ rather than $16 \mathrm{~h}$ cultures, under energized but not de-energized conditions, supports this hypothesis, since the more pronounced dissipative effect of ethanol on the $\Delta p$ in organisms cultured for $8 \mathrm{~h}$ rather than $16 \mathrm{~h}$ is only apparent under energized conditions (Cartwright et al., 1986). The linear relationship demonstrated between rates of glycine accumulation by the GAP and the magnitude of $\Delta p$, both in the presence and absence of ethanol, further illustrates the direct effect that the $\Delta p$ dissipation has on glycine uptake.

\footnotetext{
We are deeply grateful to Bruce Jacobson of the University of Massachusetts for regular supplies of cationic silica microbeads. Our thanks go also to Jill Calderbank for help in writing this paper.
} 


\section{REFERENCES}

Ahlers, J., Ahr, E. \& Seyfarth, A. (1978). Kinetic characterisation of plasma-membrane ATPase from Saccharomyces cerevisiae. Molecular and Cellular Biochemistry 22, 39-49.

Ballarin-Denti, A., Den Hollander, J. A., Sanders, D., Slayman, C. W. \& Slayman, C. L. (1984). Kinetics and pH-dependence of glycineproton symport in Saccharomyces cerevisiae. Biochimica et biophysica acta 778, 1-16.

Beavan, M. J., Charpentier, C. \& Rose, A. H. (1982). Production and tolerance of ethanol in relation to phospholipid fatty-acyl composition in Saccharomyces cerevisiae. Journal of General Microbiology 128, 1447-1455.

Borst-PaUWels, G. W. F. H. (1981). Ion transport in yeast. Biochimica et biophysica acta 650, 88-127.

Borst-Pauwels, G. W. F. H. \& Peters, P. H. J. (1981). Factors affecting the inhibition of yeast plasma membrane ATPase by vanadate. Biochimica et biophysica acta 642, 173-181.

BRADFORD, M. M. (1976). A rapid and sensitive method for the quantitation of microgram quantities of protein utilizing the principle of protein-dye binding. Analytical Biochemistry 72, 248-254.

Cartwright, C. P., Juroszek, J.-R., Beavan, M. J., RubY, F. M. S., De Morais, S. M. F. \& Rose, A. H. (1986). Ethanol dissipates the proton-motive force across the plasina membrane of Saccharomyces cerevisiae. Journal of General Microbiology 132, 369377.

DitTMER, J. C. \& Lester, R. L. (1964). A simple specific spray for the detection of phospholipids on thin-layer chromatograms. Journal of Lipid Research 5, 126-127.

Dixon, M. (1953). The determination of enzyme inhibition constants. Biochemical Journal 55, 170171.

Dufour, J. P., Goffeau, A. \& Tsong, T. Y. (1982). Active proton uptake in lipid vesicles reconstituted with a purified yeast plasma membrane ATPase. Journal of Biological Chemistry 257, 9365-9371.

EDDY, A. A. (1982). Mechanisms of solute transport into selected eukaryotic micro-organisms. Advances in Microbial Physiology 23, 1-78.

EDDY, A. A., INDGE, K. J., BACKEN, K. \& NowaCKI, J. A. (1970). Interactions between potassium ions and glycine transport in the yeast Saccharomyces carlsbergensis. Biochemical Journal 120, 845-852.

Goffeau, A. \& Slayman, C. W. (1981). The proton translocating ATPase of the fungal plasma membrane. Biochimica et biophysica acta 639, 197-223.

Gregory, M. E., Keenan, M. H. J. \& Rose, A. H. (1982). Accumulation of L-asparagine by Saccharomyces cerevisiae X-2180. Journal of General Microbiology 128, 2557-2562.

Grenson, M., Hou, C. \& Crabeel, M. (1970). Multiplicity of the amino acid permeases in Saccharomyces cerevisiae. IV. Evidence for a general amino acid permease. Journal of Bacteriology 103, 770-777.

Hanes, C. S. (1932). Studies of plant amylases. I. The effect of starch concentration upon the velocity of hydrolysis by the amylase of germinated barley. Biochemical Journal 26, 1406-1421.

Henschke, P. A., Thomas, D. S., Rose, A. H. \&
VeAZEY, F. J. (1983). Association of intracellular low-density vesicles with plasma membranes from Saccharomyces cerevisiae. Journal of General Microbiology 129, 2927-2938.

HOFSTEE, B. H. J. (1959). Non-inverted versus inverted plots in enzyme kinetics. Nature, London 184, 12961298.

IndGe, K. J., Seaston, A. \& Eddy, A. A. (1977). The concentration of glycine by Saccharomyces uvarum; role of the main vacuole and conditions leading to the explosive absorption of the amino acid. Journal of General Microbiology 99, 243-255.

INGRAM, L. O. \& BUTTKE, T. M. (1984). Effects of alcohols on micro-organisms. Advances in Microbial Physiology 25, 253-300.

Kramer, R., Kopp, F., Niedermeyer, W. \& FuHRMANN, G. F. (1978). Comparative studies of the structure and composition of the plasmalemma and the tonoplast in Saccharomyces cerevisiae. Biochimica et biophysica acta 507, 369-380.

LEÃo, C. \& VAN UdEN, N. (1982). Effect of ethanol and other alkanols on the glucose transport system of Saccharomyces cerevisiae. Biotechnology and Bioengineering 24, 2601-2604.

LEÃo, C. \& VAN UDEN, N. (1983). Effect of ethanol and other alkanols on the ammonium transport system of Saccharomyces cerevisiae. Biotechnology and Bioengineering 25, 2085-2089.

LEÃO, C. \& VAN UDEN, N. (1984). Effect of ethanol and other alkanols on the general amino acid permease of Saccharomyces cerevisiae. Biotechnology and Bioengineering 26, 403-405.

LONGLEY, R. P., Rose, A. H. \& KNIGHTS, B. A. (1968). Composition of the protoplast membrane from Saccharomyces cerevisiae. Biochemical Journal 108, 401-412.

Loureiro-Dias, M. C. \& Peinado, J. M. (1982). Effect of ethanol and other alkanols on the maltose transport system of Saccharomyces cerevisiae. Biotechnology Letters 11, 721-724.

Malpartida, F. \& Serrano, R. (1981). Proton translocation catalyzed by the purified yeast plasma membrane ATPase reconstituted in liposomes. FEBS Letters 131, 351-354.

NeAL, J. L. (1972). Analysis of Michaelis kinetics for two independent saturable membrane transport functions. Journal of Theoretical Biology 35, 113118.

Okorokov, L. A., Kulakovskaya, T. V. \& Kulaev, I. S. (1982). Solubilization and partial purification of vacuolar ATPase of yeast Saccharomyces carlsbergensis. FEBS Letters 145, 160-162.

Peters, P. H. J. \& Borst-Pauwels, G. W. F. (1979). Properties of plasma membrane ATPase and mitochondrial ATPase of Saccharomyces cerevisiae. Physiologia plantarum 46, 330-337.

RYTKA, J. (1975). Positive selection of general amino acid permease mutants in Saccharomyces cerevisiae. Journal of Bacteriology 121, 565-570.

Schatz, G., Penefsky, H. S. \& Racker, E. (1967). Partial resolution of the enzymes catalyzing oxidative phosphorylation. Journal of Biological Chemistry 242, 2552-2560.

SCHMIDT, R., ACKERMANN, R., KRATZKY, Z., WASSERMAN, B. \& JACOBSON, B. (1983). Fast and efficient 
purification of yeast plasma membranes from Saccharomyces cerevisiae. NCYC 366 Biochimica et biophysica acta 732, 421-427.

SeAston, A., Inkson, C. \& EDDy, A. A. (1973). The absorption of protons with specific amino acids and carbohydrates by yeast. Biochemical Journal 134, 1031-1043.

SERRANo, R. (1977). Energy requirements for maltose transport in yeast. European Journal of Biochemistry 80, 97-102.

SERRANO, R. (1978). Characterization of the plasma membrane ATPase of Saccharomyces cerevisiae. Molecular and Cellular Biochemistry 22, 51-63.

SERRANO, R. (1980). Effect of ATPase inhibitors on the proton pump of respiratory-deficient yeast. European Journal of Biochemistry 105, 419-424.

Stadtlander, K., RAde, S. \& Ahlers, J. (1982). Influence of growth conditions on the plasma membrane from yeast and on kinetic properties of two membrane functions. Journal of Cellular Biochemistry 20, 369-380.

Suomalainen, H. \& Nurminen, T. (1970). The lipid composition of cell wall and plasma membrane of baker's yeast. Chemistry and Physics of Lipids 4, 247256.

Thomas, D. S. \& Rose, A. H. (1979). Inhibitory effect of ethanol on growth and solute accumulation by Saccharomyces cerevisiae as affected by plasmamembrane lipid composition. Archives of Microbiology 122, 49-55.

Tuduri, P., Nso, E., Dufour, J.-P. \& Goffeau, A. (1985). Decrease of the plasma membrane $\mathrm{H}^{+}$ATPase activity during late exponential growth of Saccharomyces cerevisiae. Biochemical and Biophysical Research Communications 133, 917-922.

VAN DER Wilden, W. \& Matile, P. (1978). Isolation and characterization of yeast tonoplast fragments. Biochimie und Physiologie der Pflanzen 173, 285-294.

WiCKERHAM, L. J. (1951). Taxonomy of yeasts. I. Techniques of Classification. United States Department of Agriculture Technical Bulletin no. 1029, Washington, DC: US Department of Agriculture.

WILLSKY, G. R. (1979). Characterization of the plasma membrane $\mathrm{Mg}^{2+}$-ATPase from the yeast Saccharomyces cerevisiae. Journal of Biological Chemistry 254, 3326-3332. 